\title{
ECTIMA CONTAGIOSO EM OVINOS DA REGIÃO CENTRO-OESTE DO RIO GRANDE DO SUL
}

Rafael Costa Ebling ${ }^{1}$, João Francisco Tadiello Limana ${ }^{2}$, Gustavo Potrich Marchioretto ${ }^{2}$, Simone Stefanello ${ }^{3}$, Marta Lizandra do Rego Leal ${ }^{5}$.

1- Médico Veterinário Residente em Clínica e Cirurgia da Universidade Federal de Santa Maria (UFSM), Departamento de Clínica de Grandes Animais (DCGA), Hospital Veterinário Universitário (HVU), Avenida Roraima 1000, Cidade Universitária, CEP: 97105-900, Santa Maria, RS.

(rafaelcostaebling@gmail.com)

2- Aluno do Curso de Medicina Veterinária da UFSM.

3- Medica Veterinária, mestranda em Produção Animal. Departamento de Zootecnia, UFSM.

4- Médica Veterinária, Professora Associada do DCGA, HVU, UFSM.

Recebido em: 08/09/2015 - Aprovado em: 14/11/2015 - Publicado em: 01/12/2015 DOI: http://dx.doi.org/10.18677/Enciclopedia_Biosfera_2015_140

\begin{abstract}
RESUMO
Esse caso tem por objetivo descrever um surto de ectima contagioso em ovelhas na região de Júlio de Castilhos / RS, bem como relatar os procedimentos realizados para tratar à infecção. Em um rebanho de cinquenta e seis animais observou-se inchaço submandibular dos lábios e narinas. Lesões nas regiões coronária e interdigital dos cascos. Algumas ovelhas apresentaram infecção nos tetos. Posteriormente observou-se pústulas e crostas nas regiões afetadas. Os resultados obtidos no laboratório mostraram que as amostras foram positivas para o efeito citopáticos compatível com vírus do ectima contagioso. O tratamento das lesões foi realizado com antibiótico e uma solução a $50 \%$ de clorohexidina digliconato e de iodo degermante à $10 \%$, nas regiões lesionadas. A vacinação foi realizada em todos os animais do rebanho. Observou-se melhora acentuada dos sinais clínicos e das lesões que afetaram o rebanho. Não houve nenhum caso de morte no rebanho em virtude da infecção pelo vírus do ectima contagioso.
\end{abstract}

PALAVRAS-CHAVE: vírus, infecção, pústulas, tratamento, vacina.

\section{CONTAGIOUS ECTHYMA IN SHEEP FROM MIDWEST OF RIO GRANDE DO SUL}

\begin{abstract}
This case aims to describe an outbreak of contagious ecthyma in sheep in the region of Julio de Castilhos/RS, as well as reporting procedures performed to treat the infection. In a herd of fifty-six animals was observed submandibular swelling of lips and nostrils. Lesions in coronary and interdigital regions of the hooves. Some sheep had infection in mammary tits. Later there was pustules and crusts in the affected regions. The results obtained in the laboratory showed that the samples were positive for cytopathic effect compatible with contagious ecthyma virus. Treatment of the lesions was performed with antibiotics and a $50 \%$ solution of chlorhexidine ENCICLOPÉDIA BIOSFERA, Centro Científico Conhecer - Goiânia, v.11 n.22; p.1042 2015
\end{abstract}


digliconato $2 \%$ and iodo degermante to $10 \%$ in the damaged regions. Vaccination was performed in all animals from the herd. There was marked improvement of clinical signs and lesions that affected the herd. There were no cases of death in the herd due to infection by the virus of contagious ecthyma.

KEYWORDS: sheep, ecthyma, crusts, treatment, vaccine.

\section{INTRODUÇÃO}

O ectima contagioso é uma doença vírica também conhecida como dermatite pustular ovina, ou mais comumente por boqueira. O vírus do ectima é um Vírus DNA pertencente à família poxviridae, enquadrado no gênero parapoxvírus. Os vírus desse gênero são potencialmente zoonóticos, podendo afetar pessoas que trabalham diretamente com esses animais, como criadores, veterinários, tosadores e ordenadores (MAYR, 1981; CANAL, 2007; SCHMIDT et al., 2012; KOUFAKIS et al., 2014). A doença afeta principalmente ovinos e caprinos, podendo infectar outros pequenos ruminantes. Alguns casos já foram relatados em bovinos e caninos. Sabese que a doença ocorre no Rio Grande do Sul (RIET-CORREA et al., 2001), apesar de não haver dados epidemiológicos precisos. Também há relatos de surtos de ectima contagioso em ovinos e caprinos em distintos estados brasileiros (RIETCORREA et al., 2001; NOBREGA et al., 2008; SCHMIDT et al., 2012; GOUVEIA et al., 2014).

É sabido que o vírus é mantido em todas as regiões do mundo em que se tem criação de ovinos e caprinos, mantem-se nas populações por infecções cruzadas ou por crostas secas, que permanecem infectantes por meses ou até anos. Além de pastagens, currais, cercas e estábulos também podem servir de fonte de contaminação para os animais, sendo inclusive local preferencial para a contaminação, devido ao fato do vírus ser menos resistente às mudanças de temperatura e umidade, estando mais protegido do tempo nas instalações. A contaminação geralmente ocorre por ferimentos em locais contaminados. Pastagens abrasivas são importantes fontes de infecção, introduzindo o vírus na mucosa oral. Dificilmente o vírus invade a pele intacta (MAYR,1981; CANAL, 2007; RIETCORREA et al., 2001).

Acredita-se que o aparecimento da doença em propriedades livres se dá pelo transporte de animais de fora da propriedade, como reprodutores ou matrizes. Esses animais são levados às fazendas sem apresentarem sintomas, que podem aparecer logo após a chegada devido à imunossupressão causada pelo estresse do transporte e mudança de ambiente (RIET-CORREA et al., 2001; PINHEIRO et al., 2003; SARDI et al., 2012). Outra forma de transporte é mediante uso de utensílios usados na criação, como tesouras de tosquiadores e material de casqueamento (RIET-CORREA et al., 2001; PINHEIRO et al., 2003).

A infecção pode ocorrer direta ou indiretamente. O período de incubação varia entre dois e seis dias e regride aproximadamente 25 dias após o aparecimento das primeiras lesões. A caracterização da doença se dá por lesões nos lábios e boca, podendo estar presente em todas as regiões do corpo desprovidas de lã, principalmente em tetos de ovelhas em lactação, região interdigital e genitálias. Iniciam como pápulas que progridem rapidamente para pústulas, e depois para crostas espessas que cobrem uma grande área de pele. Quando essas crostas são retiradas revelam tecido de granulação. Outros sinais clínicos são dificuldade respiratória devido à edemaciação do focinho, dificuldade na ingestão de alimentos e 
amamentação. A doença pode desenvolver-se de maneira generalizada e afetar faringe e esôfago. (CANAL, 2007; RIET-CORREA et al., 2001).

A enfermidade pode afetar animais de várias idades, infectando preferencialmente animais em período crítico de suas vidas, como cordeiros lactentes, animais após-desmame e ovelhas em aleitamento. Em animais adultos as lesões geralmente são menos acentuadas. A morbidade é alta, atingindo até $100 \%$, mas a mortalidade é baixa e ocorre principalmente por infecções secundárias às miíases (ex.: Cochliomyia macellaria) e às broncopneumonias, tendo como principais agentes responsáveis o Fusobacterium necrophorum, o Dermatphilus congolensis e o Staphylococcus spp (RIET-CORREA et al., 2001; PINHEIRO et al., 2003).

Apesar de mortalidade ser baixa, as perdas econômicas devido à inanição são grandes, principalmente em cordeiros que são incapazes de realizar a mamada em decorrência das lesões localizadas nos tetos das mães. Os cordeiros apresentam considerável retardo no crescimento, e os animais adultos acentuada perda de peso. A ocorrência de mamites devido ao impedimento da mamada, e consequente acúmulo de leite na glândula mamária, é frequente, podendo ocasionar o descarte das ovelhas (CANAL, 2007; RIET-CORREA et al., 2001).

A vacinação embora não confira proteção clínica completa, tem sido utilizada com relativo sucesso no controle da doença em vários países. A dificuldade de se obter essa proteção deve-se a capacidade do vírus de re-infectar os seus hospedeiros, apesar da resposta imunológica (HAIG, 2006; FLEMING \& MERCER, 2007). Diferentes tipos de vacinas contra o ORFV já foram produzidas, mas a que contém o vírus replicativo, sem prévia atenuação, ainda é a mais utilizada em vários países (NANDI et al., 2011) inclusive no Brasil (CANAL, 2007).

O presente relato de caso teve por objetivo descrever a ocorrência de um surto de ectima contagioso em propriedade rural de Júlio de Castilhos/RS, relatar os procedimentos realizados, bem como apresentar os resultados obtidos após o tratamento dos animais.

\section{MATERIAL E METODOS}

A equipe da Clínica de Ruminantes do Hospital Veterinário Universitário da Universidade Federal de Santa Maria (HVU-UFSM) foi chamada para atendimento de um rebanho ovino de 56 animais, com idade variando de cinco meses a quatro anos, sem raça definida. Os animais estavam alocados em campo nativo e não recebiam suplementação alimentar ou mineral. Um mês antes do surto, havia sido introduzido no rebanho um carneiro para a temporada reprodutiva.

Segundo o relato do criador, 15 dias após a compra do reprodutor, os animais começaram a apresentar edema submandibular, de lábios e fossas nasais, com posterior surgimento de pústulas e crostas nas regiões afetadas. Alguns animais já apresentavam dificuldade respiratória e na ingestão de alimentos, bem como lesões na borda coronária dos membros locomotores.

A equipe realizou três visitas à propriedade. Em um primeiro momento, realizou-se a avaliação clínica desses animais, assim como a coleta de amostras das crostas. Na inspeção geral observou-se um rebanho heterogêneo, com peso variando de 20 à $70 \mathrm{~kg}$ e escore corporal bom, com notas de 3 a 4, segundo os métodos utilizados por (DE MEDEIROS, G. R. et al. 2009) que consistiu na palpação da região dorsal da coluna vertebral, atribuindo-se nota de 1 a 5 , em que 1 representa um animal caquético e 5, um animal obeso.. As pústulas e crostas estavam presentes em $90 \%$ dos animais. 
Quando do exame físico observou-se edema submandibular, pústulas e crostas nos lábios e nas fossas nasais (Figura 1). Alguns animais exibiram lesão interdigital e na borda coronária dos cascos, bem como nos tetos, sugerindo uma provável infecção pelo parapoxvírus. Foi então realizado a coleta de crostas das lesões e as amostras foram enviadas ao Laboratório de Virologia da Universidade Federal de Santa Maria.

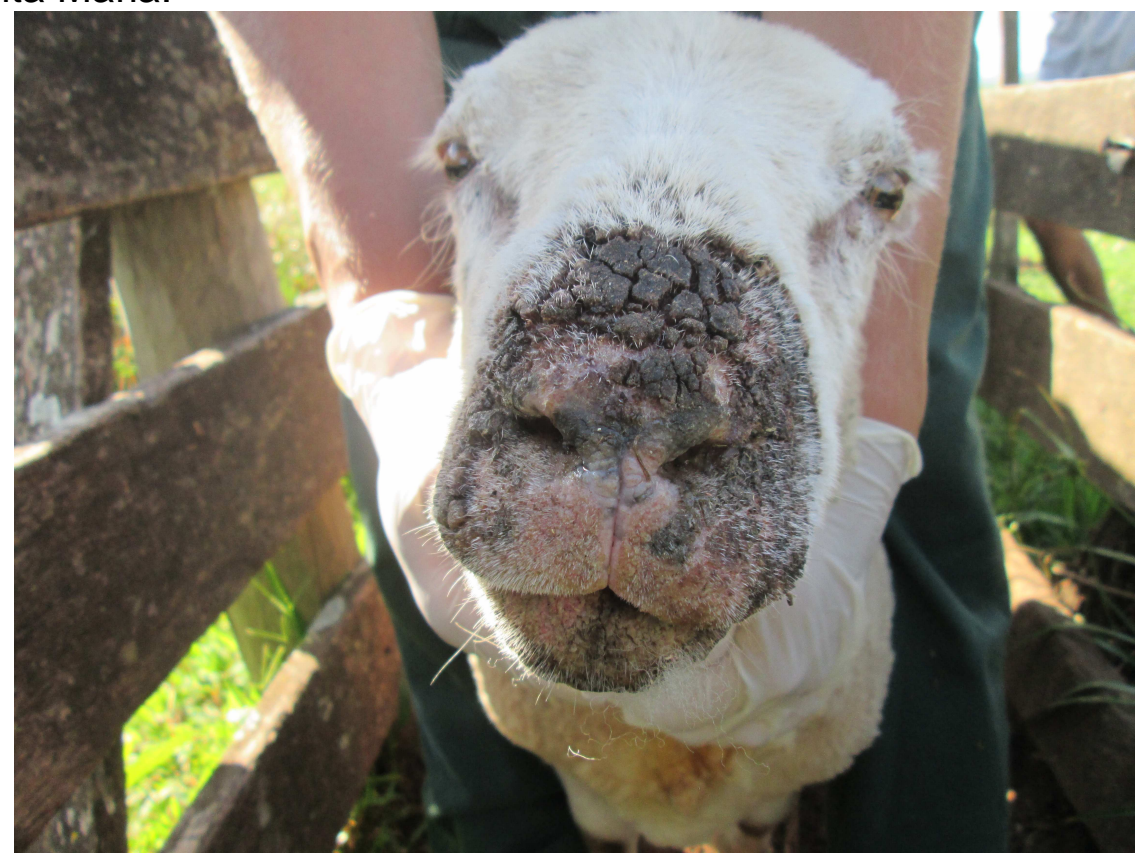

FIGURA 1. Ovino no 01, diagnosticado com Ectima Contagioso. Presença de crostas e edema na região nasolabial (Arquivo Pessoal)

Ainda na primeira visita, realizou-se antibioticoterapia, com administração intramuscular de penicilina benzatina de longa ação em dose única, e aplicou-se uma solução de $50 \%$ de digliconato de clorexidine $(2 \%$ ) e $50 \%$ de iodo degermante $(10 \%)$ nas regiões afetadas. Todos os procedimentos foram realizados com uso de luvas de procedimento para evitar o contato das mãos com as lesões, uma vez que se trata de uma doença de caráter zoonótico. Recomendou-se ao proprietário que repetisse o tratamento local uma vez ao dia durante uma semana e que evitasse o contato direto com as lesões.

Passando-se 15 dias após a primeira visita, obteve-se o resultado laboratorial com resultado das amostras positivo para efeito citopático compatível com o vírus do ectima contagioso. Na segunda visita (após resultado laboratorial), efetuou a vacinação massiva (ectimavac® - Vallé) de todo rebanho. O modo de aplicação da vacina foi mediante escarificação da pele com espátula apropriada para este fim, com posterior aplicação de três gotas da vacina sobre o local. Após 15 dias, realizou-se uma terceira visita, com a finalidade de acompanhamento do quadro clinico. Observou-se uma redução acentuada dos sinais clínicos e das lesões nos animais do rebanho (figura 2.) não havendo óbito de nenhum animal. 


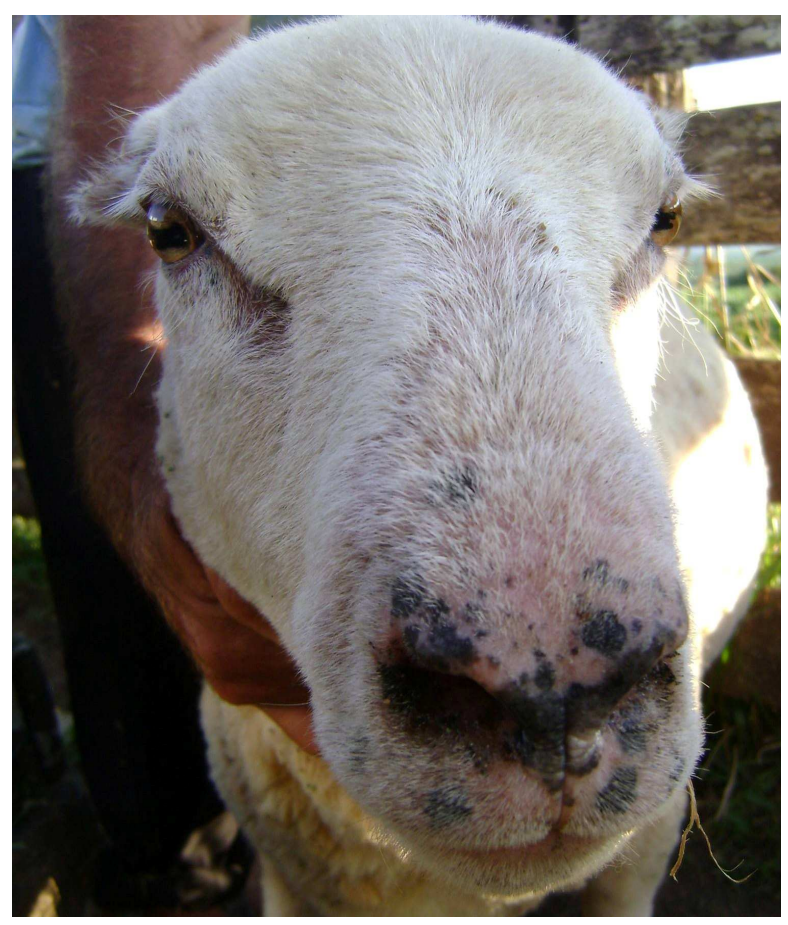

FIGURA 2. Ovino no 01, após 30 dias da vacinação e tratamento. Redução acentuada das crostas e do edema (Arquivo pessoal)

\section{RESULTADOS E DISCUSSÃO}

Um surto de ectima contagioso foi estudado no interior de Júlio de Castilhos, Rio Grande do Sul, o caso foi acompanhado e observou-se significativa melhora após o tratamento. Que consistiu em vacinar o rebanho e promover assepsia das lesões.

Segundo estimativas da FAO (2007), o mercado da carne ovina tem evoluído bastante nos últimos anos e, embora a ovinocultura de corte ainda seja uma atividade de pouca expressão econômica dentro do agronegócio brasileiro, tem apresentado expressivo crescimento, tanto na produção como na formalização da produção e no consumo, com tendências positivas e expectativas animadoras para todo o segmento. Para evitar perdas econômicas, vacinas contra o vírus ectima contagioso são comercializadas no Brasil, como a exemplo em muitos países, as quais possuem sua eficácia questionável. Por outro lado, a grande população ovina do país (aproximadamente 17 milhões de cabeças (IBGE, 2010), aliadas com a grande disseminação da doença e os prejuízos que esta causa, justificam o interesse pelo uso de vacinas eficazes e seguras no tratamento desta.

As lesões observadas no presente surto, com infecções em diferentes categorias também são relatadas por NOBREGA et al. (2008) que descreveram surtos de ectima contagioso no semiárido da Paraíba, onde animais jovens e cabras lactentes foram os mais afetados. As lesões surgiram no rebanho após a introdução de um reprodutor de fora da propriedade. Conforme descrito por SARDI et al.2012, animais expostos a viagem e a ambiência a um novo rebanho pode ativar o vírus que pode estar em latência, com isso a introdução de animais no rebanho sem o conhecimento do histórico dos mesmos e sem a realização da quarentena pode introduzir o vírus na propriedade. 
Conforme descrito pela literatura (RIET-CORREA et al., 2001) os principais fatores que predispõem a morte de animais infectados por ectima, são as infecções secundárias por parasitas ou bactérias. Um exame clínico realizado adequadamente, com tratamento local das pústulas e crostas a base de antissépticos, com administração de antibióticos de longa ação evita contaminações secundárias que poderiam ser fatais. A ausência de infecções e de consequentes óbitos nesse rebanho evidenciou a grande importância de se impedir as infecções secundarias.

A característica da doença é a responsável pelas perdas econômicas causadas pela infecção (NOBREGA et al., 2008). As pústulas dificultam a alimentação dos animais, acarretando num déficit de crescimento e acentuada perda de peso. O Tratamento e a vacinação mostraram-se eficientes na resolução da doença, com regressão dos sintomas, permitindo consumo adequado de alimento pelos animais. Visto que uma alimentação adequada é de suma importância para o adequado funcionamento do sistema imune, para o ganho de peso e, consequente, aproveitamento produtivo desse rebanho, o tratamento e vacinação dos animais infectados assume papel fundamental para se evitar as perdas econômicas causadas pela doença.

\section{CONCLUSÃO}

Os cuidados com a entrada de animais e uso de objetos e instalações contaminadas com ectima contagioso são de suma importância na ovinocultura, visto que o vírus é altamente transmissível e tem uma morbidade elevada, afetando significativamente a produção do rebanho. Conforme observado e descrito na literatura o exame clínico é na maioria das vezes suficiente para um diagnóstico presuntivo da doença. No entanto, é fundamental o envio de amostras para análise laboratorial uma vez que trata-se de infecção que deve ser diferenciada de outras doenças vesiculares, bem como pelo seu caráter zoonótico. A vacinação do rebanho é eficiente e rápida na resolução das lesões, e o tratamento para evitar infecções secundárias é fundamental para diminuir o risco de óbito dos animais.

\section{REFERÊNCIAS}

CANAL, C.W., Poxviridae. In: FLORES, E.F. Virologia Veterinária. Ed. da Universidade Federal de Santa Maria, v.1, cap. 18. p. 506-508, 2007.

FLEMING S.B. \& MERCER A.A. Genus Parapoxvirus, In: MERCER A.A. (Ed.), Poxviruses. Birkauser, Berlin. v.1, p.127-166, 2007.

FOOD AND AGRICULTURE ORGANIZATION OF THE UNITED NATIONS - FAO. Food outlook, Rome: GIEWS-FAO, v.1, n.2, p. 91, 2007.

GOUVEIA, A.M.G.; SILVA, M.X.; MAIA, J.M.S.; BRANDÃO, H.M.; SEYFFERT, N.; MIYOSHI, A.; AZEVDO, V., GUIMARÃES, G.S. Technological level and epidemiological aspects of sheep husbandry in Minas Gerais, southeastern Brazil. Pesquisa Veterinária Brasileira, cap 34, p. 865-868, 2014.

HAIG D.M. Orf virus infection and host immunity. Current Opinion Infection Diseases, cap.19 p.127-131, 2006. 
IBGE 2010. Instituto Brasileiro de Geográfia e Estatística. Dísponivel em $>$ http//www.ibge.gov.br/home/presidencia/noticias/noticia_impressao.php?id_noticia= 1761> Acesso em 25 ago. 2015.

DE MEDEIROS, G. R.; RAMOS DE CARVALHO, F.F.R.; BATISTA, A.M.V.; JÚNIOR, W.M.D.; SANTOS, G.R.A.; DE ANDRADE, D.K.B. Efeito dos níveis de concentrado sobre as características de carcaça de ovinos Morada Nova em confinamento. Revista Brasileira Zootecnia v.38, n.4, p.718-727, 2009.

KOUFAKIS, T; KATSAITIS, P; GABRANIS, I. Orf disease: a report of a case. Brazilian Journal of Infectious Diseases. v.18, n.5, p. 568-569, 2014.

MAYR, A.; GUERREIRO, M.G. Virologia veterinária. v.2, p.423-426, 1981.

NANDI S., UJJWAL K. \& CHOWDHURY S. Current status of contagious ecthyma or orf disease in goat and sheep: A global perspective. Small Ruminant Research. Cap. 96, p. 73-82, 2011.

NOBREGA, J.E.; MACEDO, J.T.C.A.; ARAÚJO, J.A.S.; DANTAS, A.F.M.; SOARES, M.P.; RIET-CORREA, F. Ectima contagioso em ovinos e caprinos no semiárido da Paraíba, Rio de Janeiro. Pesquisa Veterinária Brasileira. v.28, n.3, p. 135139, 2008.

PINHEIRO, R.Z.; CHAGAS, A.C.S.; ANDRIOLI, A.; ALVES, F.S.F. Viroses de Pequenos Ruminantes. v.1, p.18-20, 2003.

RIET-CORREA, F.; SCHILD, A.L.; MENDEZ, M.D.C.; LEMOS, R.A.A. Doenças de equinos e ruminantes. v.1, p. 408-418, 2001.

SARDI, S. I; NETO, A. L. M.; OLIVEIRA, A.; AGAPITO, R.; SERAFIM, W.; SAMPAIO, M.; MULLER, C.; TORRES, J. A.; CAMPOS, G. S. Primeiro relato do vírus Orf em rebanhos caprinos do semiárido brasileiro. Revista Instituto Adolfo Lutz, São Paulo. v.71, n.3, p.597-600, 2012.

SCHMIDT, C.; CARGNELUTTI,J.F.; MARTINS, M.; WEIBLEN,R.; EDUARDO FURTADO FLORES E. F. Vacina experimental produzida em cultivo celular confere proteção parcial contra o ectima contagioso em ovinos. Pesquisa Veterinária Brasileira cap.32, n.1, p.11-16, 2012. 